\title{
QUALITÄT
}

Liebe Leserin, lieber Leser,

fast wöchentlich erreichen mich Anfragen von findigen Tüftlern, die einen Fachartikel über ein neues Motorenkonzept in der MTZ veröffentlichen wollen. In der Regel haben sie sehr viel Zeit, Energie und auch Geld in ihre Erfindung investiert, die die Motorentechnik revolutionieren soll. Allerdings liegen von den exotischen Konstruktionen oftmals nur Grafiken, bunte Präsentationen oder Konstruktionszeichnungen vor, bestenfalls steht in der Garage ein Prototypenmotor aus alten Motorenteilen, der schon erste Lebenszeichen in Form von Verpuffungen von sich gegeben hat. Doch genau hier liegt der Hase im Pfeffer: Die MTZ ist den Lesern, also Ihnen, verpflichtet. In nunmehr 73 Jahren haben wir uns einen weltweiten Ruf als technischwissenschaftliches Fachorgan erarbeitet, den es zu halten gilt. Speziell bei neuen Motorenkonzepten achten wir daher darauf, dass neben Simulationsergebnissen auch Resultate von Prüfstandsuntersuchungen realer Motoren vorliegen. Dabei müssen zumindest Leistungswerte, Verbrauch und Emissionen nach aktuellen Testzyklen abgeprüft sein, gegebenenfalls ergänzt durch weiterreichende Messungen, etwa dem NVH-Verhalten. Uns geht es hier um den seriösen Beweis des Potenzials eines neuen Motorenkonzepts, nicht um Technokratie ihrer selbst willen. Ich bin davon überzeugt, dass diese bewährte Praxis ein Baustein für die hohe Qualität der Veröffentlichungen in der MTZ ist.

Zudem haben wir auch schon vor vielen Jahren ein transparentes und gerechtes Prozedere der Beitragsauswahl für unsere Fachzeitschriftenfamilie erarbeitet: Anhand eines Abstracts entscheiden wir in der Redaktionskonferenz, ob ein vorgeschlagener Beitrag in die MTZ passt. Kriterien sind neben Neuigkeitswert und zu erwartender technischer Tiefe der Ausarbeitung unter anderem auch die Relevanz hinsichtlich aktueller Fragestellungen der Branche. Diese Bewertungskriterien dienen uns als Maßstab für alle Beitragsvorschläge, egal ob sie vom oben genannten Hobby-Tüftler oder aus der F\&E-Abteilung eines Großunternehmens stammen.

Für uns zählt seriöse und substanzielle Technikdokumentation fernab von werbedurchwirktem Marketingjournalismus. Wollen Sie uns auf diesem Weg unterstützen? Bestimmt gibt es auch in Ihrem Unternehmen Neuentwicklungen, die es wert sind, in der MTZ veröffentlicht zu werden. Ich lade Sie ein, mir Beitragsvorschläge in Form eines kurzen Abstracts zuzusenden. Senden Sie Ihre Artikelangebote oder schreiben Sie Ihre Meinung zum Thema Qualitätsjournalismus an Richard.Backhaus@springer.com.

Herzlichst, Ihr

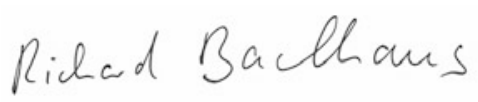

\section{RICHARD BACKHAUS,}

Stellvertretender Chefredakteur Wiesbaden, 10. September 2012

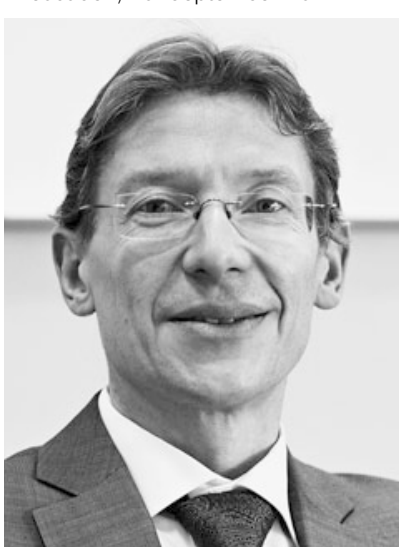

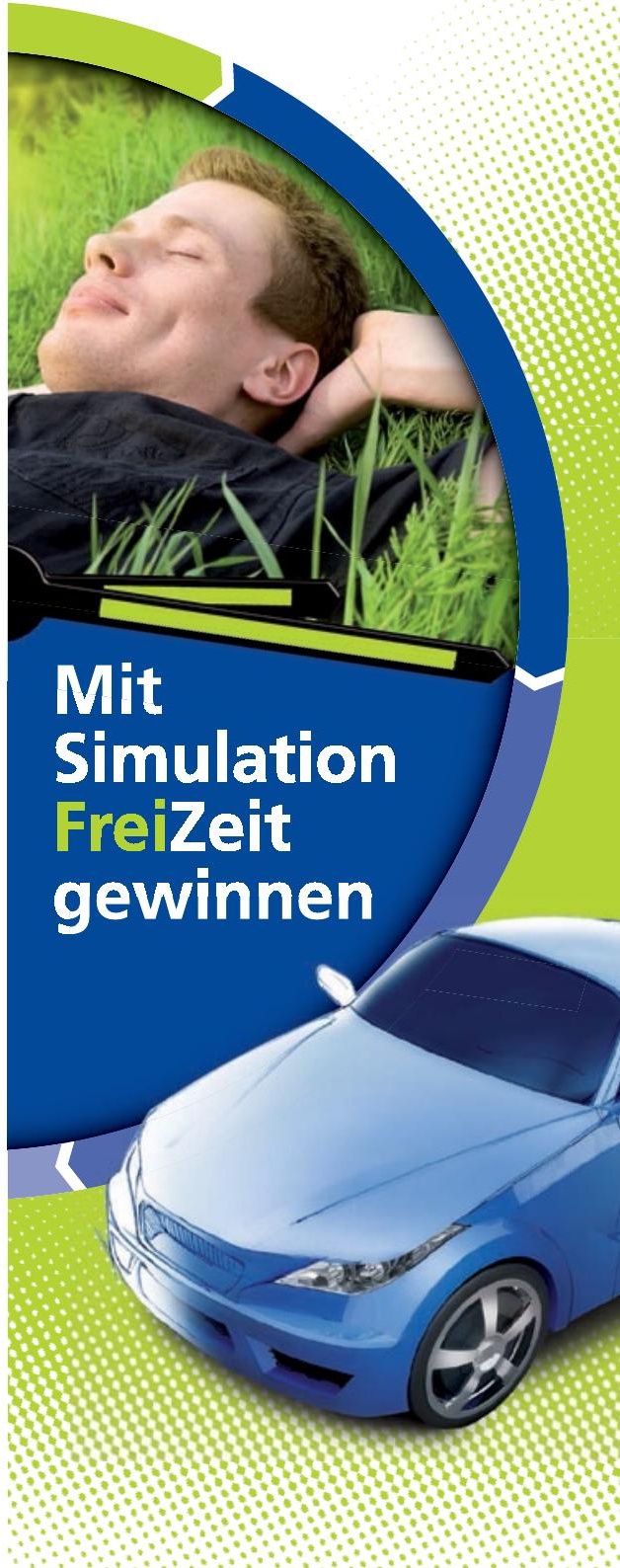

Ihre Zeit-Vorteile

- Umfangreiche Variantenvergleiche durchführen

- Schnell zu ersten Einschätzungen gelangen

- Komplexe Fragestellungen transparent analysieren

\section{Für die Bereiche}

- Fahrleistung und Verbrauch

- Fahrerassistenzsysteme

- Fahrdynamik

- Motordynamik

- Elektro- und Hybridfahrzeuge

Mehr erfahren und am FreiZeit-Gewinnspiel teilnehmen

www.tesis-dynaware.com/freizeit 